Reprod. Nutr. Dévelop., 1984, 24 (2), 155-164.

\title{
Le problème de la sécrétion de testostérone par le testicule embryonnaire de Poulet : nouvelles recherches
}

\author{
J.-P. WENIGER, J. CHOURAQUI, A. ZEIS
}

Laboratoire de Zoologie et d'Embryologie expérimentale, Université Louis-Pasteur,

12, rue de I'Université, 67000 Strasbourg, France.

Summary. The problem of testosterone secretion by the chick embryo testis : further studies.

The aim of this study was to determine whether the chick embryo testis was able to convert dehydroepiandrosterone and androstenedione into testosterone.

Testes from 17-19 day old chick embryos were cultured in vitro in the presence of tritiated dehydroepiandrosterone or androstenedione of high specific activity, and the radioactive testosterone formed was isolated by thin-layer chromatography and identified by recrystallization to constant specific activity.

Parallel experiments with mouse embryo testes showed that these methods were valid. However, since specific activity with chick embryo testes was very low and could not be brought to constancy, testosterone could not be identified with these testes.

It is concluded that the 17-19 day old chick embryo testis cannot form testosterone from either dehydroepiandrosterone or androstenedione. This conclusion is in keeping with the absence of a physiological role for testosterone in the male chick embryo.

\section{Introduction.}

Depuis 1966, la réalité de la sécrétion de testostérone par le testicule embryonnaire d'Oiseau a été affirmée dans de nombreux travaux. Parmi les plus récents, nous citerons ceux de Guichard et al. (1979) et de Woods et al. (1983) sur l'embryon de Poulet et d'Ottinger et Bakst (1981), de Scheib et al. (1981) et de Guichard et al. (1983) sur l'embryon de Caille.

Pourtant, dès 1969, I'un de nous (Weniger, 1969 et 1970) avait signalé l'impossibilité de démontrer la formation de testostérone par le testicule embryonnaire de Poulet, s'opposant ainsi à Haffen et Cédard (1968). Les travaux ultérieurs consacrèrent le désaccord entre les deux groupes d'auteurs (Cédard et al., 1970 ; Guichard et al., 1973 ; Weniger et Zeis, 1973, 1976 et 1977). Mais il est vrai que l'utilisation de précurseurs marqués au ${ }^{14} \mathrm{C}$, d'activité spécifique relativement faible, n'était pas particulièrement propice à la détection de faibles quantités de tes- 
tostérone. Aussi, pouvait-on envisager de reprendre ces recherches en utilisant des précurseurs tritiés, d'une activité spécifique 1000 fois supérieure à celle des molécules marquées au ${ }^{14} \mathrm{C}$ utilisées antérieurement. Ce projet s'est imposé à nous après la publication des travaux de Guichard et al. (1979) et de Woods et al. (1983) dont il convient maintenant de dire un mot.

Le travail de Woods et al. (1983) concerne le dosage radioimmunologique de la testostérone dans le plasma d'embryons de Poulet mâles de 7 à 21 jours. Comparées à celles d'un travail antérieur du même laboratoire (Woods et al., 1975), les valeurs de la testostéronémie trouvées par Woods et al. (1983) sont nettement plus élevées entre les stades de 11 et 17 jours. De plus, si Woods et al. (1975) avaient trouvé des différences selon le sexe, la testostéronémie étant systématiquement plus faible dans le sexe femelle, celles-ci n'ont pas été confirmées par Gasc et Thibier (1979), qui donnent en outre des valeurs nettement plus faibles que Woods et al. (1975) et a fortiori que Woods et al. (1983).

Le travail de Guichard et al. (1979) concerne la détermination, par radioimmunologie, des quantités de testostérone sécrétées par les gonades d'embryons de Poulet mâles et femelles de 15 et 18 jours cultivées sur des milieux contenant ou non de la prégnénolone, de la déhydroépiandrostérone ou de l'androstènedione. II donne lieu aux remarques suivantes. Les grandes quantités de testostérone trouvées dans les milieux de culture additionnés d'androstènedione peuvent s'expliquer par l'importance de la réaction croisée de l'immunsérum anti-testostérone avec ce stéroïde $(0,7 \%)$. D'une façon analogue, l'absence de réaction croisée de l'immunsérum anti-testostérone avec la prégnénolone suffit à expliquer que les quantités de testostérone trouvées soient grosso modo les mêmes dans les milieux témoins et dans ceux additionnés de prégnénolone. Par contre, dans le cas de la déhydroépiandrostérone, la réaction croisée $(0,01 \%)$ ne contribue que pour une part minime aux quantités de testostérone trouvées. Aussi, tout au moins en ce qui concerne la déhydroépiandrostérone, peut-on suivre les auteurs quand ils concluent à son utilisation par les gonades des 2 sexes et à sa transformation en testostérone. Mais on comprend difficilement que les testicules ne produisent pas plus de testostérone que les gonades femelles, comme on comprend mal leur incapacité à utiliser la prégnénolone comme précurseur.

On se trouvait donc en présence de résultats favorables à la thèse de la sécrétion de testostérone par le testicule embryonnaire de Poulet, mais qui n'étaient pas inattaquables. Notre travail n'avait d'autre but que d'essayer de clarifier le débat en étudiant la capacité du testicule embryonnaire de Poulet à transformer la déhydroépiandrostérone $-{ }^{3} \mathrm{H}$ et l'androstènedione $-{ }^{3} \mathrm{H}$ en testostérone $-{ }^{3} \mathrm{H}$.

\section{Matériel et méthodes.}

Matériel biologique. - Découpés en trois ou quatre, les testicules mis en culture provenaient d'embryons de Poulet de race Leghorn blanche âgés de 16 à 19 jours. A titre dé comparaison, nous avons aussi cultivé quelques testicules d'embryon de Souris Swiss de 14 et 19 jours découpés en deux.

Culture d'organes. - Le milieu de culture était le milieu 199, dont 0,7 ml garnissaient la logette de la boîte de Pétri pour culture d'organes « Falcon ». Les 
explants représentant 3-4 paires de testicules étaient placés sur un disque de papier filtre " Durieux » auquel le milieu 199 affleurait. Ils étaient ensuite baignés dans 3-4 $\mu$ de la solution du précurseur radioactif répartis sur le filtre $(1 \mu)$ par paire de testicules). L'incubation était faite à $37^{\circ} \mathrm{C}$ pendant $24 \mathrm{~h}$ dans une atmosphère enrichie en oxygène et en gaz carbonique.

Précurseurs radioactifs. - L'androstènedione-1, 2, 6, 7-3 H et la déhydroépiandrostérone-1, 2, 6, 7-3 $\mathrm{H}$ utilisées provenaient du Radiochemical Centre (Amersham) ; leur pureté radiochimique était de $97 \%$ et leur activité spécifique respectivement de 69 et $64 \mathrm{Ci} / \mathrm{mmol}$. Elles étaient mises en solution dans le mélange propane-1,2-diol-liquide de Tyrode $1: 3$ à la concentration radioactive de $0,30-0,39 \mu \mathrm{Ci} / \mu \mathrm{l}$, qui correspondait à une concentration molaire approximativement $5 \mu \mathrm{M}$.

Extraction de la testostérone, chromatographie et recristallisations. - Au terme des $24 \mathrm{~h}$ de culture, le milieu a été recueilli. Le disque de papier filtre, ainsi que les explants, ont été rincés avec $3 \times 0,5 \mathrm{ml}$ de liquide de Tyrode, qui ont été ajoutés au milieu de culture. Le milieu et les liquides de rinçage, additionnés de $100 \mu \mathrm{g}$ de testostérone non radioactive comme entraîneur, ainsi que d'une quantité traceuse de testostérone $-{ }^{14} \mathrm{C}$ (New England Nuclear, Boston), ont été extraits par $3 \times 10 \mathrm{ml}$ d'éther éthylique. Les extraits éthérés ont été réunis et concentrés à $0,2 \mathrm{ml}$, qui ont été déposés sur une couche mince de gel de silice.

Après une double chromatographie dans le système de solvants chloroformeéther éthylique $9: 1$, la testostérone est repérée aux rayons $U V$, puis on enregistre la répartition de la radioactivité sur la couche mince au moyen d'un lecteur de radiochromatogrammes. La zone de la couche mince où a migré la testostérone est recueillie, la testostérone est éluée, puis acétylée. Après chromatographie dans le système de solvants cyclohexane-acétate d'éthyle $7: 3$, l'acétate de testostérone est mélangé à $20 \mathrm{mg}$ de produit non radioactif et recristallisé alternativement dans les systèmes méthanol-dichlorométhane-éther de pétrole et méthanolchloroforme-éther de pétrole. Les cristaux mettent plusieurs jours à se former et se présentent sous la forme de prismes et de rhomboèdres enchevêtrés.

Après chaque recristallisation, on prélève environ $1 \mathrm{mg}$ de cristaux et environ $1 \mathrm{mg}$ d'eaux-mères, qui sont ensuite repesés à $0,008 \mathrm{mg}$ près à l'aide d'une micro-balance. La mesure de la radioactivité se fait au moyen d'un compteur à scintillation en milieu liquide dont les fenêtres sont réglées de telle sorte à éviter tout passage de ${ }^{3} \mathrm{H}$ dans la voie $\mathrm{du}{ }^{14} \mathrm{C} .12 \%$ de ${ }^{14} \mathrm{C}$ passent dans la voie $\mathrm{du}{ }^{3} \mathrm{H}$ et sont déduits de l'activité totale dans cette voie. Dans ces conditions, le rendement du comptage est de $60 \%$ pour le ${ }^{14} \mathrm{C}$ et de $33 \%$ pour le ${ }^{3} \mathrm{H}$, le bruit de fond étant respectivement de 15 et $10 \mathrm{coups} / \mathrm{min}$. Le comptage est prolongé le temps qu'il faut pour réduire l'incertitude au seuil de $95 \%$ à moins de $3 \%$. Dans ces conditions, l'incertitude sur la détermination de l'activité spécifique est inférieure à $5 \%$. Conformément au critère établi par Axelrod et al. (1965), l'activité spécifique sera considérée comme constante, et par conséquent l'acétate de testostérone identifié, si, au cours de 3 recristallisations successives, l'écart entre les valeurs extrêmes et la moyenne est inférieur à $5 \%$. 
Ajoutons que l'activité spécifique par rapport au ${ }^{14} \mathrm{C}$ permet de calculer le pourcentage de récupération, dont il sera tenu compte dans le calcul du pourcentage de transformation des précurseurs tritiés en testostérone.

\section{Résultats.}

Une expérience préliminaire était destinée à vérifier que testostérone tritiée et testostérone marquée au ${ }^{14} \mathrm{C}$ subissaient les mêmes pertes au cours de l'analyse. Les résultats consignés dans le tableau 1 indiquent un pourcentage de récupération identique pour les 2 isotopes. L'utilisation de testostérone- ${ }^{14} \mathrm{C}$ pour l'évaluation des pertes de la testostérone- ${ }^{3} \mathrm{H}$ est donc licite.

Dans les 2 premières expériences, l'addition de testostérone- ${ }^{14} \mathrm{C}$ au milieu de culture avant l'analyse avait été omise à dessein, 'afin de limiter l'enregistrement de la radioactivité aux seuls métabolites tritiés (fig. 1-4). Le radiochromatogramme 1 se rapportant aux testicules embryonnaires de Poulet montre que la zone de la testostérone est active, mais on voit sur le radiochromatogramme 2 que l'activité accompagnant l'acétate de testostérone ne diffère pas du bruit de fond à la sensibilité maximale de l'appareil. En revanche, dans le cas des testicules embryonnaires de Souris, le pic de radioactivité associé à la testostérone (fig. 3) reste associé à l'acétate de testostérone (fig. 4). Cette expérience démontre que la testostérone sécrétée dans le milieu de culture est aisément décelable.

Dans les expériences suivantes, une quantité traceuse de testostérone- ${ }^{14} \mathrm{C}$ avait été ajoutée au milieu de culture avant l'analyse, de telle sorte que le pourcentage de récupération a pu être déterminé. Le tableau 2 donne les conditions expérimentales et les résultats dans le cas de l'utilisation de la déhydroépidandrostérone- ${ }^{3} \mathrm{H}$ comme précurseur, les données du tableau 3 se rapportant à l'utilisation de l'androstènedione- ${ }^{3} \mathrm{H}$.

\section{TABLEAU 1}

Comparaison des pourcentages de récupération de la testostérone tritiée et de la testostérone marquée au ${ }^{14} \mathrm{C}$.

Activité spécifique (AS) exprimée en coups $/ \mathrm{min} / \mathrm{mg}$. Les valeurs constantes sont encadrées.

\begin{tabular}{|c|c|c|}
\hline & Testostérone-3 ${ }^{3} \mathrm{H}$ & Testostérone- ${ }^{14} \mathrm{C}$ \\
\hline 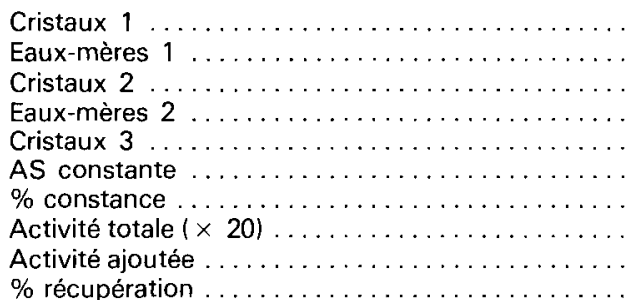 & $\begin{array}{|ll|}2 & 417 \\
2 & 448 \\
2 & 424 \\
2 & 400 \\
2 & 387 \\
2 & 415 \\
1,4 \% \\
48304 \\
56490 \\
86\end{array}$ & \begin{tabular}{c|}
687 \\
672 \\
693 \\
680 \\
663 \\
679 \\
$2,4 \%$ \\
13580 \\
15960 \\
85
\end{tabular} \\
\hline
\end{tabular}




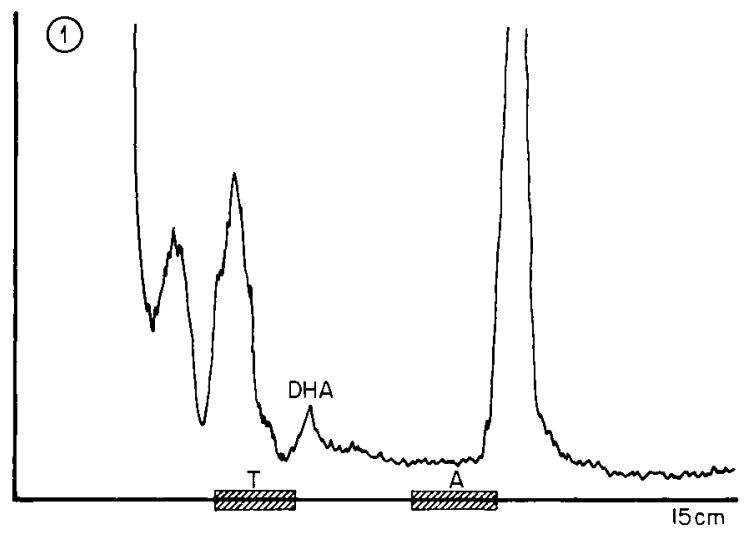

FIG. 1. - Radiochromatogramme des métabolites formés à partir de déhydroépiandrostérone ${ }^{-3} \mathrm{H}$ par 30 paires de testicules embryonnaires de Poulet de 16 jours.

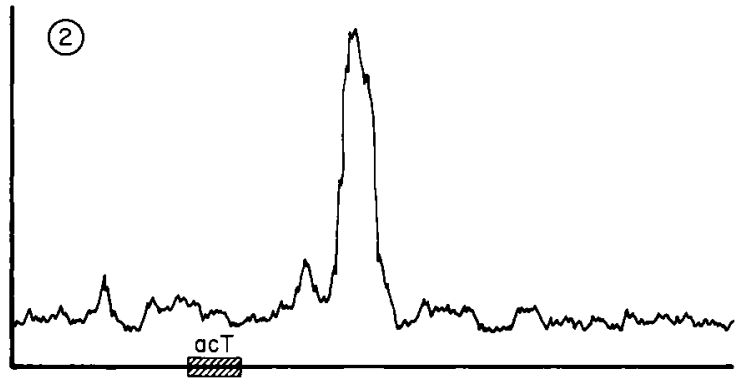

FIG. 2. - Radiochromatogramme obtenu après élution de la testostérone et acétylation.

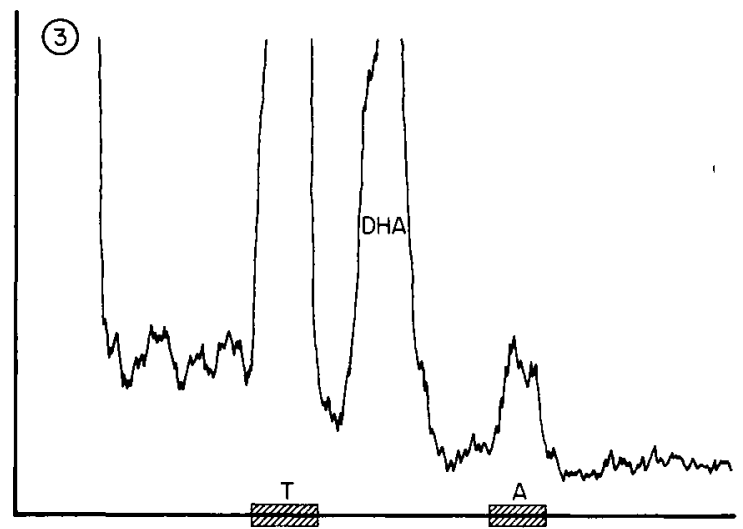

FIG. 3. - Radiochromatogramme des métabolites formés à partir de déhydroépiandrostérone- ${ }^{3} \mathrm{H}$ par 5 paires de testicules embryonnaires de Souris de 19 jours. 


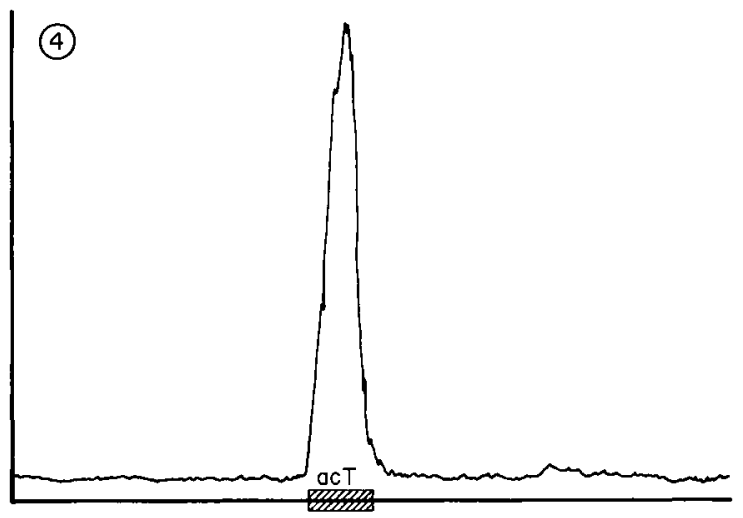

FIG. 4. - Radiochromatogramme obtenu après élution de la testostérone et acétylation. Explication des graphiques dans le texte. $A$ : androstènedione: $T$ : testostérone; DHA: déhydroépiandrostérone.

Comme il ressort de l'examen des 2 tableaux, la seule expérience où la constance de l'activité spécifique par rapport au ${ }^{3} \mathrm{H}$ ait été obtenue est l'expérience 6 , où les testicules provenaient d'embryons de Souris. Dans ce cas, la testostérone est donc identifiée et sa formation à partir de déhydroépiandrostérone démontrée. Dans tous les autres cas, où les testicules provenaient d'embryons de Poulet, l'activité spécifique était soit nulle soit subissait des fluctuations irrégulières. Mais admettons que dans chaque cas la valeur la plus faible corresponde à de l'acétate de testostérone pur. Les pourcentages de transformation qu'on obtient dans ces conditions sont infimes, de l'ordre de $0,05 \%$, et sans commune mesure avec les $37 \%$ qui figurent dans la colonne 6 se rapportant aux testicules embryonnaires de Souris.

\section{Discussion.}

Comme il s'agit d'un travail où les méthodes employées sont d'une importance capitale commençons par discuter les conditions de nos expériences.

Utiliser la déhydroépiandrostérone et l'androstènedione tritiées aux concentrations 86-87 $\mu \mathrm{M}$ auxquelles Guichard et al. (1979) avaient utilisé ces mêmes substances à l'état non radioactif eût été trop coûteux. De plus, de telles concentrations pouvaient paraître excessives. Mais en déposant la solution radioactive sur le filtre, au lieu de la mélanger d'emblée aux $0,7 \mathrm{ml}$ de milieu, nous avons réalisé un gradient de concentrations allant de $5 \mu \mathrm{M}$ à $7 \mathrm{nM}$ en fin de diffusion. Que ces conditions sont propices à l'utilisation des précurseurs et à leur transformation en testostérone est attesté par l'expérience 2 ayant trait aux testicules embryonnaires de Souris (fig. 3 et 4). L'absence de pic de radioactivité dans la zone de l'acétate de testostérone sur la figure 2 se rapportant aux testicules embryonnaires de Poulet signifie que dans ce cas la formation de testostérone a été insignifiante, à moins d'admettre que les pertes de testostérone aient été pratiquement 


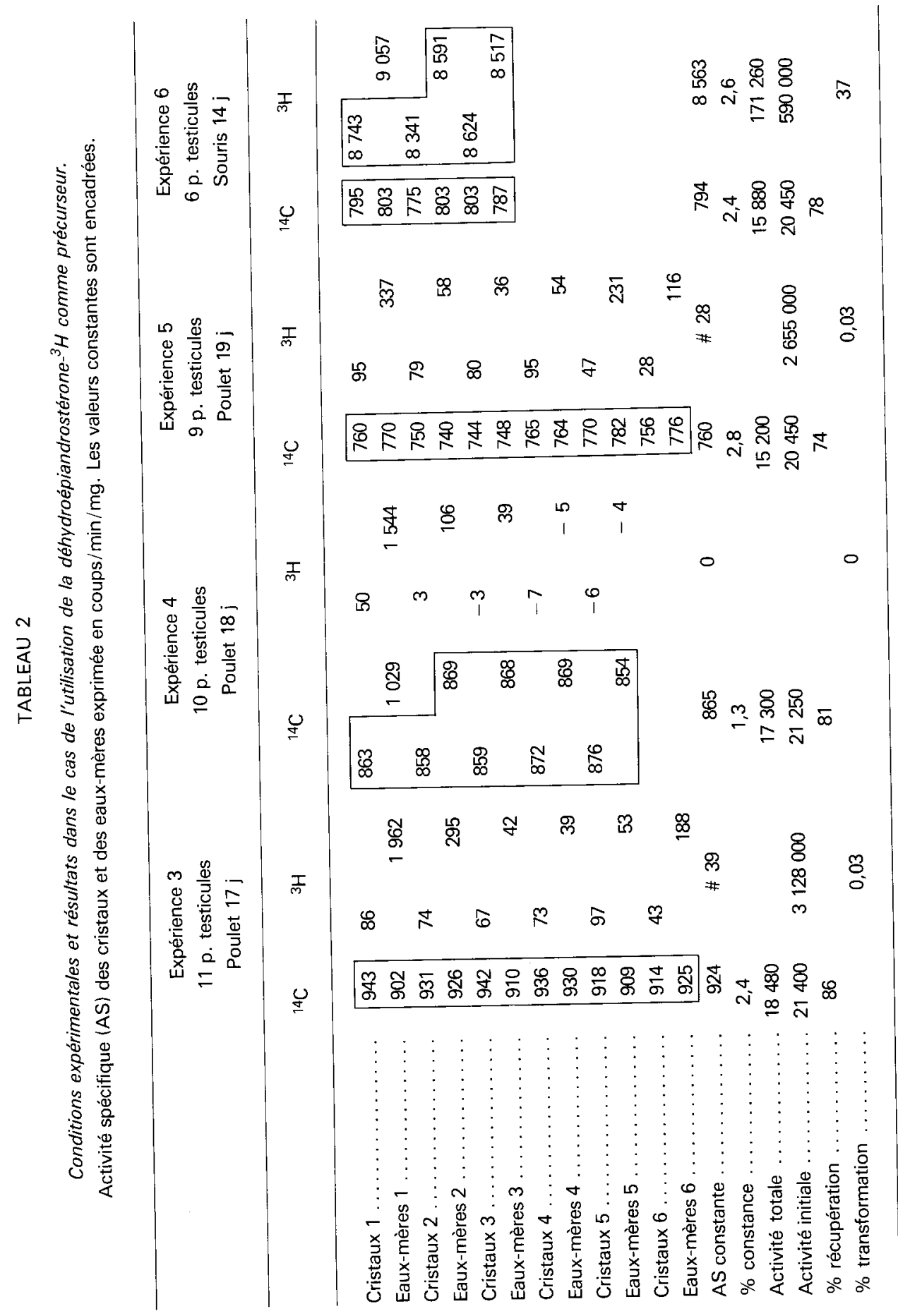


TABLEAU 3

Conditions expérimentales et résultats dans le cas de l'utilisation de l'androstènedione ${ }^{3} \mathrm{H}$ comme précurseur.

Activité spécifique (AS) des cristaux et des eaux-mères exprimée en coups/min/mg. Les valeurs constantes sont encadrées.

\begin{tabular}{|c|c|c|c|c|c|}
\hline \multirow[b]{3}{*}{ 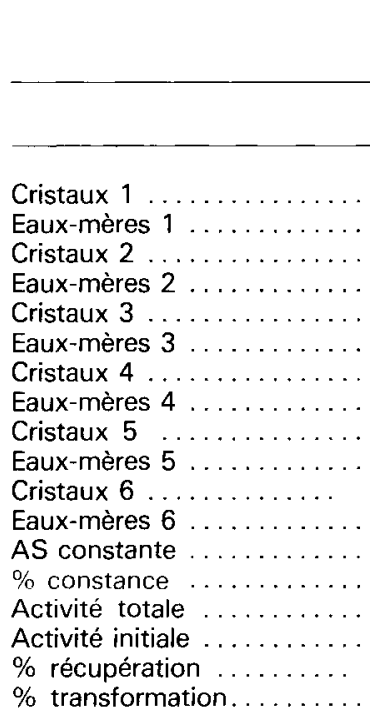 } & \multicolumn{3}{|c|}{$\begin{array}{c}\text { Expérience } 7 \\
10 \text { p. testicules Poulet } 17 \mathrm{j} .\end{array}$} & \multicolumn{2}{|c|}{$\begin{array}{c}\text { Expérience } 8 \\
12 \mathrm{p} . \text { testicules Poulet } 17 \mathrm{j} .\end{array}$} \\
\hline & \multicolumn{2}{|c|}{${ }^{14} \mathrm{C}$} & ${ }^{3} \mathrm{H}$ & ${ }^{14} \mathrm{C}$ & ${ }^{3} \mathrm{H}$ \\
\hline & $\left\{\begin{array}{l}846 \\
844 \\
849 \\
844 \\
829\end{array}\right.$ & $\begin{array}{l}952 \\
862 \\
859\end{array}$ & $\begin{array}{rr}98 & \\
79 & 8435 \\
81 & 153 \\
77 & 104 \\
101 & 44 \\
& 33\end{array}$ & \begin{tabular}{c|c|}
892 \\
872 \\
913 \\
911 \\
917 \\
925 \\
921 \\
927 \\
915 \\
- \\
927 \\
907 \\
912 \\
4,3 \\
18240 \\
21400 \\
85
\end{tabular} & $\begin{array}{rr}138 & 6753 \\
103 & \\
92 & 343 \\
107 & 253 \\
116 & 76 \\
& \\
144 & - \\
& 72 \\
& \# 72\end{array}$ \\
\hline
\end{tabular}

totales. Mais la grande uniformité du pourcentage de récupération dans les expériences ultérieures rend cette hypothèse invraisemblable.

Ensuite il y a lieu de s'arrêter aux conditions de recristallisation, puisque d'elles dépendent les résultats sur lesquels est basée l'identification de la testostérone. L'utilisation de systèmes de solvants purement organiques garantit une recristallisation lente, évitant au maximum l'emprisonnement de molécules étrangères dans le réseau cristallin. Néanmoins, une certaine syncristallisation s'est produite, vraisemblablement en raison d'une grande similitude de structure de l'un ou l'autre métabolite avec la testostérone. Mais cette syncristallisation est très irrégulière, se traduisant par des fluctuations de l'activité spécifique n'obéissant à aucune loi (tabl. 2 et 3 ). Si de tels résultats ne permettent pas d'affirmer l'identité de la testostérone, ils ne permettent pas non plus d'exclure formellement la formation de traces de testostérone, comme il a été dit plus haut. Nous nous trouvons donc en face du dilemme suivant : le testicule embryonnaire de Poulet sécrète-t-il des traces de testostérone ou bien n'en sécrète-t-il pas du tout ? Etant donné que dans l'expérience 4 des conditions de recristallisation sans doute éminement favorables ont permis d'obtenir une activité spécifique nulle, nous inclinons vers l'absence totale de sécrétion de testostérone.

Ce point de vue est corroboré par l'absence d'action biologique du testicule embryonnaire de Poulet sur les organes effecteurs de la testostérone: 1) A 
l'inverse du testicule embryonnaire de Souris, le testicule embryonnaire de Poulet ne stimule pas le développement du canal de Wolff d'embryon de Souris en culture in vitro (Weniger, 1965 ; Weniger et Zeis, 1980). 2) A l'inverse du testicule embryonnaire de Rat, le testicule embryonnaire de Poulet ne stimule pas le développement du canal de Wolff d'embryon de Poulet (Chouraqui et al., 1980). De plus, il $n^{\prime} y$ a pas de signe de sécrétion de testostérone avant la $3^{e}$ semaine chez le poussin mâle, quand commence la différenciation de l'épididyme (Maraud, 1963). Enfin, si le testicule embryonnaire de Poulet de 17 jours renferme de rares cellules de Leydig présomptives, elles n'ont pas les caractères ultrastructuraux typiques de cellules stéroïdogènes actives (Carlon et Erickson, 1978).

La question est alors de savoir comment Haffen et Cédard (1968) et Guichard et al. (1973 et 1979) ont pu affirmer la production de testostérone par le testicule embryonnaire de Poulet. En ce qui concerne les expériences radiochimiques (Haffen et Cédard, 1968 ; Guichard et al., 1973), I'utilisation de systèmes de solvants aqueux pour les recristallisations a pu empêcher une purification efficace. Quant aux dosages radioimmunologiques (Guichard et al., 1979), on peut penser à un manque de spécificité de l'immunsérum anti-testostérone.

\section{Conclusion.}

En conclusion, à la question posée dans ce travail nous apportons une réponse négative : le testicule embryonnaire de Poulet de 17-19 jours est incapable de transformer la déhydroépiandrostérone et l'androstènedione en testostérone. Cette conclusion rejoint l'absence de rôle physiologique reconnu à la testostérone chez l'embryon de Poulet.

Reçu en septembre 1983.

Accepté en novembre 1983.

\section{Références}

AXELROD L. R., MATTHIJSSEN C., GOLDZIEHER J. W., PULLIAM P. E., 1965. Definitive identification of microquantities of radioactive steroids by recrystallization to constant specific activity. Acta endocrin., suppl. 99, 7-66.

CARLON N., ERICKSON G. F., 1978. Fine structure of prefollicular and developing germ cells in the male and female left embryonic chick gonads in vitro with and without androgenic steroids. Ann. Biol. anim. Bioch. Biophys., 18, 335-349.

CÉDARD L., GUICHARD A., HAFFEN K., 1970. Métabolisme de la prégnénolone-7 $\alpha^{-3} \mathrm{H}$ et de la progestérone-4- ${ }^{14} \mathrm{C}$ par les gonades embryonnaires de Poulet cultivées in vitro. C. R. Acad. Sci. Paris, 271 (Série D), 1707-1710.

CHOURAQUI J., ZEIS A., WENIGER J.-P., 1980. Etude comparative en culture in vitro de I'action des testicules embryonnaires de Poulet et de Rat sur le canal de Wolff d'embryon de Poulet. Arch. Anat. micr. Morph. exp., 69, 167-173.

GASC J.-M., THIBIER M., 1979. Plasma testosterone concentration in control and testosteronetreated chick embryos. Experientia, 35, 1411-1412. 
GUICHARD A., CÉDARD L., HAFFEN K., 1973. Aspect comparatif de la synthèse de stéroïdes sexuels par les gonades embryonnaires de Poulet à différents stades du développement (étude en culture organotypique à partir de précurseurs radioactifs). Gen. comp. Endocrin., 20, 16-28.

GUICHARD A., CEEDARD L., MIGNOT Th.-M., SCHEIB D., HAFFEN K., 1979. Radioimmunoassay of steroids produced by chick embryo gonads cultured in presence of some exogenous steroid precursors. Gen. comp. Endocrin., 39, 9-19.

GUICHARD A., MIGNOT Th. M., CÉDARD L., ANGUELOVA P., SCHEIB D., 1983. Control of the hormonal secretions of quail embryo gonads (normal and DES-treated) : in vitro effects of testosterone and of hCG. Gen. comp. Endocrin., 51, 347-352.

HAFFEN K., CÉDARD L., 1968. Etude, en culture organotypique in vitro, du métabolisme de la déhydroépiandrostérone et de la testostérone radioactives par les gonades normales et intersexuées de l'embryon de Poulet. Gen. comp. Endocrin., 11, 220-234.

MARAUD R., 1963. Recherches expérimentales sur les facteurs inducteurs de la formation de l'épididyme du Coq (Gallus gallus). Arch. Anat. micr. Morph. exp., 52, 83-127.

OTTINGER M. A., BAKST M. R., 1981. Peripheral androgen concentrations and testicular morphology in embryonic and young male Japanese quail. Gen. comp. Endocrin., 43, 170177.

SCHEIB D., GUICHARD A., MIGNOT Th. M., CÉDARD L., 1981. Steroidogenesis by gonads of normal and of diethylstillbestrol-treated quail embryos: radioimmunoassays on organ cultures. Gen. comp. Endocrin., 43, 519-526.

WENIGER J.-P., 1965. Etude comparée des actions hormonales des testicules embryonnaires de Poulet et de Souris en culture in vitro. Arch. Anat. micr. Morph. exp., 54, 909-919.

WENIGER J.-P., 1969. Recherches sur la nature chimique des hormones sexuelles embryonnaires de Poulet. Ann. Embr. Morph., 2, 433-444.

WENIGER J.-P., 1970. Le testicule embryonnaire de Poulet sécrète-t-il de la testostérone ? Arch. Anat. Hist. Embr., 53, 97-105.

WENIGER J.-P., ZEIS A., 1973. Recherches sur la nature chimique de l'hormone testiculaire de l'embryon de Poulet. Ann. Embr. Morph., 6, 219-228.

WENIGER J-P., ZEIS A., 1976. Androgènes et régression des canaux de Müller chez l'embryon de Poulet : nouvelles recherches. Arch. Anat. Hist. Embr., 59, 19-32.

WENIGER J.-P., ZEIS A., 1977. Hormone anti-müllérienne d'Oiseau et testostérone. Arch. Anat. Hist. Embr., 60, 189-196.

WENIGER J.-P., ZEIS A., 1980. Etude comparative de l'action du testicule embryonnaire de Poulet et de la testostérone sur divers organes effecteurs en culture in vitro. Arch. Anat. Hist. Embr., 63, 179-188.

WOODS J. E., RUTHERFORD J. E., THOMMES R. C.,"1983. Functional development of the hypothalamic-adenohypophyseal-testicular axis in the chick embryo. Gen. comp. Endocrin., 50, 235-241.

WOODS J. E., SIMPSON R. M., MOORE P. L., 1975. Plasma testosterone levels in the chick embryo. Gen. comp. Endocrin., 27, 543-547. 